\title{
IMMUNOHISTOCHEMICAL STUDY OF VON WILLEBRAND'S FACTOR AS A MARKER OF ENDOTHELIAL DYSFUNCTION OF UTERO-PLACENTAL AREA AND MYOMETRIUM IN PREGNANCY
}

\author{
Olena A. TIULIENIEVA ${ }^{1}$, Igor S. DAVYDENKO ${ }^{1}$, Oleksandra V. GARVASIUK ${ }^{1 凶}$, \\ Anastasiia V. HOIAN ${ }^{2}$ \\ ${ }^{1}$ Department of Pathological anatomy, Higher State Educational Establishment of Ukraine „Bukovinian \\ State Medical University (BSMU)“, Ukraine \\ ${ }^{2}$ Higher State Educational Establishment of Ukraine „Bukovinian State Medical University (BSMU)“, \\ Ukraine
}

Received 22 Jan 2019, Accepted 15 May 2019

https://doi.org/10.31688/ABMU.2019.54.3.17

\begin{abstract}
Introduction. During pregnancy, the uterus suffers a huge number of morphological changes. Placental changes lead to an adequate supply of the fetus and a normal process of childbirth. In particular, the uterine-placental area appears where the fertilized ovum attaches to the uterus. Myometrium increases in size and changes the spatial configuration.
\end{abstract}

The objective of the study was to assess the relative immunohistochemical concentration of the von Willebrand's factor in endothelial cells of different types of vessels of the uterine-placental area and myometrium in pregnancy.

Material and methods. The biopsy material was obtained from pregnant women during the cesarean section. Three parts (central, pericentral, peripheral) of each biopsy were developed. Multiple paraffin sections were stained in three ways: 1) immunohistochemical von Willebrand's factor staining with an

\section{Résumé}

Étude immunohistochimique du facteur de von Willebrand en tant que marqueur de la dysfonction endothéliale de la zone utéro-placentaire et du myomètre dans la grossesse

Introduction. Pendant la grossesse, l'utérus subit un grand nombre de changements morphologiques. Les changements placentaires conduisent à un apport suffisant du foetus et à un processus normal d'accouchement. En particulier, la région utérine-placentaire apparaît quand l'ovule fécondé se fixe à l'utérus. Le myomètre augmente de taille et modifie la configuration spatiale.

L'objectif de l'étude était de développer la relative concentration immunohistochimique du facteur de von Willebrand dans les cellules endothéliales de différents types de vaisseaux de la région utérine-placentaire et du myomètre pendant la grossesse. 
antigen thermal exposure (DACO); 2) differentiated histochemical fibrin and collagen Slinchenko's staining; 3) hematoxylin-eosin staining. Digital images were analyzed with a computer program ImageJ $(1.48 \mathrm{v}, \mathrm{W}$. Rasband, National Institute of Health, USA, 2015). We also calculated the arithmetic mean and its average error for optical density (computer program PAST 3.19, Ø.Hammer, 2018).

Results. The method was tested in 65 pregnant women during the cesarean section. The main results of the staining quantitative analysis in myometrium are: 1). Arterial type vessels $0.415 \pm 0.0029$ units of optic density; 2). Venous type vessels $0.381 \pm 0.0024$ units of optic density; 3). Microcirculatory system $0.375 \pm 0.0022$ units of optic density. The main results of the staining quantitative analysis in uterine-placental area are 1). Arterial type vessels $0.404 \pm 0.0027$ units of optic density; 2). Venous type vessels $0.380 \pm 0.0024$ units of optic density; 3). Microcirculatory system $0.373 \pm 0.0021$ units of optic density.

Conclusions. Immunohistochemical study of von Willebrand's factor allows investigation of the endothelial dysfunction in all types of vessels of both UPA and myometrium. This is very promising for the early detection of placental dysfunction and establishing of morphological preconditions for fetal insufficiency.

Keywords: uterine-placental area, myometrium, pregnancy, von Willebrand's factor.

Abbreviations list: uterine-placental area (UPA); von Willebrand's factor (vWF), Ob - objective, Oc - ocular.

\section{INTRODUCTION}

During pregnancy, the uterus suffers a huge number of morphological changes ${ }^{1,2}$, which leads to an adequate supply of the fetus and a normal process of childbirth ${ }^{3,4}$. In particular, the uterine-placental area (UPA) appears where the fertilized ovum attaches to the uterus, while myometrium is increasing in size and is changing the spatial configuration ${ }^{5,6}$, spiral arteries of UPA and myometrium are changing gestationally. Pathology of UPA can be determined by histological structure of the chorionic villi, as well as by immunohistochemical changes in accumulation of specific placental proteins in trophoblast - hormones (placental lactogen and chorionic gonadotropin), the enzyme
Méthodes. Le matériel de biopsie a été obtenu des femmes enceintes pendant la césarienne au moyen de notre propre technique. Trois parties (centrale, péricentrale, périphériques) de chaque biopsie ont été développées. Plusieurs sections de paraffine ont été colorées de trois manières différentes: 1) la coloration immunohistochimique du facteur de von Willebrand avec une exposition thermique antigénique; 2) la coloration histochimique de Slinchenko différenciée à la fibrine et au collagène; 3) la coloration à l'hématoxyline-éosine. Les images numériques ont été analysées avec un programme informatique ImageJ $(1.48 \mathrm{v}, \mathrm{W}$. Rasband, Institut national de la santé, USA, 2015). Nous avons également calculé la moyenne arithmétique et son erreur moyenne pour densité optique (programme informatique PAST 3.19, Ø.Hammer, 2018).

Résultats. La méthode a été testée chez 65 femmes enceintes au cours de la césarienne. Les principaux résultats de l'analyse quantitative de la coloration dans le myomètre sont 1). Vaisseaux de type artériel 0,415 $\pm 0,0029$; 2) Vaisseaux de type veineux $0,381 \pm 0,0024$; 3) Système de microcirculation $0,375 \pm 0,0022$. Les principaux résultats de l'analyse quantitative de la coloration dans la région utérine-placentaire sont : 1). Vaisseaux de type artériel 0,404 $\pm 0,0027$; 2) Vaisseaux de type veineux $0,380 \pm 0,0024$; 3) Système de microcirculation $0,373 \pm 0,0021$.

Conclusions. L'étude immunohistochimique du facteur de von Willebrand permet l'étude du dysfonctionnement endothélial dans tous les types de vaisseaux de la région utérine-placentaire et du myomètre, ce qui est très prometteur pour la détection précoce du dysfonctionnement placentaire et l'établissement des conditions morphologiques préalables à l'insuffisance fœetale.

Mots-clés: région utérine-placentaire, myomètre, grossesse, facteur de von Willebrand.

placental alkaline phosphatase and vimentin ${ }^{7,8}$. There are different ways to study the morphology of UPA and myometrium, but the most effective is the use of different types of biopsies of these structures? These biopsies can be performed during the cesarean section ${ }^{10}$. The biopsies material allows using the entire spectrum of modern morphological research methods, including immunohistochemical method ${ }^{11}$. Immunohistochemical studies on von Willebrand's factor (vWF) in various aspects of pregnancy are at the beginning of their development ${ }^{12}$. Material of UPA and myometrium of the pregnant uterus have not been investigated on the (vWF) yet ${ }^{13,14}$; therefore, the methodological approaches of using this technique on the specified material are not defined ${ }^{15}$. 
Table 1. Optical density of vWF in different types of vessels in myometrium and UPA $(M \pm m)$

\begin{tabular}{ccc}
\hline & $\begin{array}{c}\text { Myometrium } \\
\text { (units of optic density) }\end{array}$ & $\begin{array}{c}\text { UPA } \\
\text { (units of optic density) }\end{array}$ \\
\hline Arterial type vessels & $0.415 \pm 0.0029^{*}$ & $0.404 \pm 0.0027^{*}$ \\
\hline Venous type vessels & $0.381 \pm 0.0024^{* *}$ & $0.380 \pm 0.0024^{* *}$ \\
\hline Microcirculatory system & $0.375 \pm 0.0022^{* *}$ & $0.373 \pm 0.0021^{* *}$ \\
\hline$*$ - two samples are significantly different, p<0,05 & & \\
* - two samples are NOT significantly different & & \\
\hline
\end{tabular}

The OBJeCtive OF THE STUDY was to assess the relative immunohistochemical concentration of the $\mathrm{vWF}$ in endothelial cells of different types of vessels of the UPA and myometrium in pregnancy.

\section{Materials AND Methods}

The biopsy material was obtained from 65 pregnant women during the cesarean section.

The investigation took place during 2014-2018 years at the Department of pathological anatomy of Higher Educational Establishment „Bukovinian State Medical University“ (Chernivtsi, Ukraine). The biomaterial for this research was taken on the basis of patient's informed consent for taking the utero-placental area and myometrium during the C-section in Kamyanets-Podilsky maternity hospital. Material harvesting and research design were approved by the Biomedical Ethics Committee of Bukovinian State Medical University.

Three parts (central, pericentral, peripheral) of each biopsy were fixed in $10 \%$ neutral buffered formalin solution for 22-24 hours, with further ethanol dehydration and paraffin embedding. Multiple paraffin sections $(5 \mathrm{mkm})$ were stained in three ways: 1) immunohistochemical vWF staining with an antigen thermal exposure (DACO); 2) differentiated histochemical fibrin and collagen Slinchenko's staining (Malory`s analogue techniques); 3) hematoxylin-eosin staining.

Optic density of specific staining was measured in relative units of optic density, by means of computer micro densitometry method (from 0 - absence of staining, absolute transparency; to 1 - maximal staining, absolute non-transparency) by means of computer program ImageJ (version $1.48 \mathrm{v}$, free license, W.Rasband, National Institute of Health, USA, 2015). Optic density of staining was applied as a measure of immunohistochemical concentration ${ }^{16}$.

Arithmetic mean and its error were calculated. The groups were compared by means of bilateral unpaired Student's criterion in the medium of computer program PAST 3.15 (free license), Ø. Hammer, $2018^{17}$. Preliminary testing for the norm was made in samples by means of Shapiro-Wilki method. The differences were considered statistically significant if $p \leq 0,05$.

\section{Results}

The positive staining of $\mathrm{vWF}$ was observed in endothelial cells in all types of blood vessels, but the color intensity was different. To establish a numeric value of the staining and to verify its difference in obedience to the type of vessel and the localization (myometrium or UPA), we defined the optical density (Table 1).

The biggest value of optical density was in arterial type vessels, and its value depended on localization - density was significantly higher in myometrium arteries (Fig. 1), smaller in venous type vessels and the smallest in endothelial cells of microcirculatory system (Fig. 2, 3). In these structures, optical density did not depend on localization.

In the lumen of the blood vessels we found vWF positive filamentous structures with varying color intensity, shape and size (Fig. 1). Those structures were located near the vessel wall or closed the vessel lumen completely or partially. Since those structures seems to be thrombi, we studied them by means of the Slinchenko's histochemical technique, which is usually used for specific fibrin detection. Assumption about the nature of these objects was confirmed; the objects contained fibrin, and therefore were thrombi. However, it was noted that in the material from some women filamentous and formless intravascular structures were found more often in the case of using vWF staining than the Slinchenko's staining. Thus, we can suggest that in thrombotic formation vWF accumulates in the vessels' lumen earlier than fibrin.

The obtained results of the study of vWF staining are promising for the evaluation of endothelial dysfunction in different types of vessels, and for the arteries - in different localizations (myometrium or UPA).

During the study of the sections with immunohistochemical staining, in the lumens of the vessels the desquamated endothelial cells were found (Fig. $1,2,3)$. This finding is important for verification of 

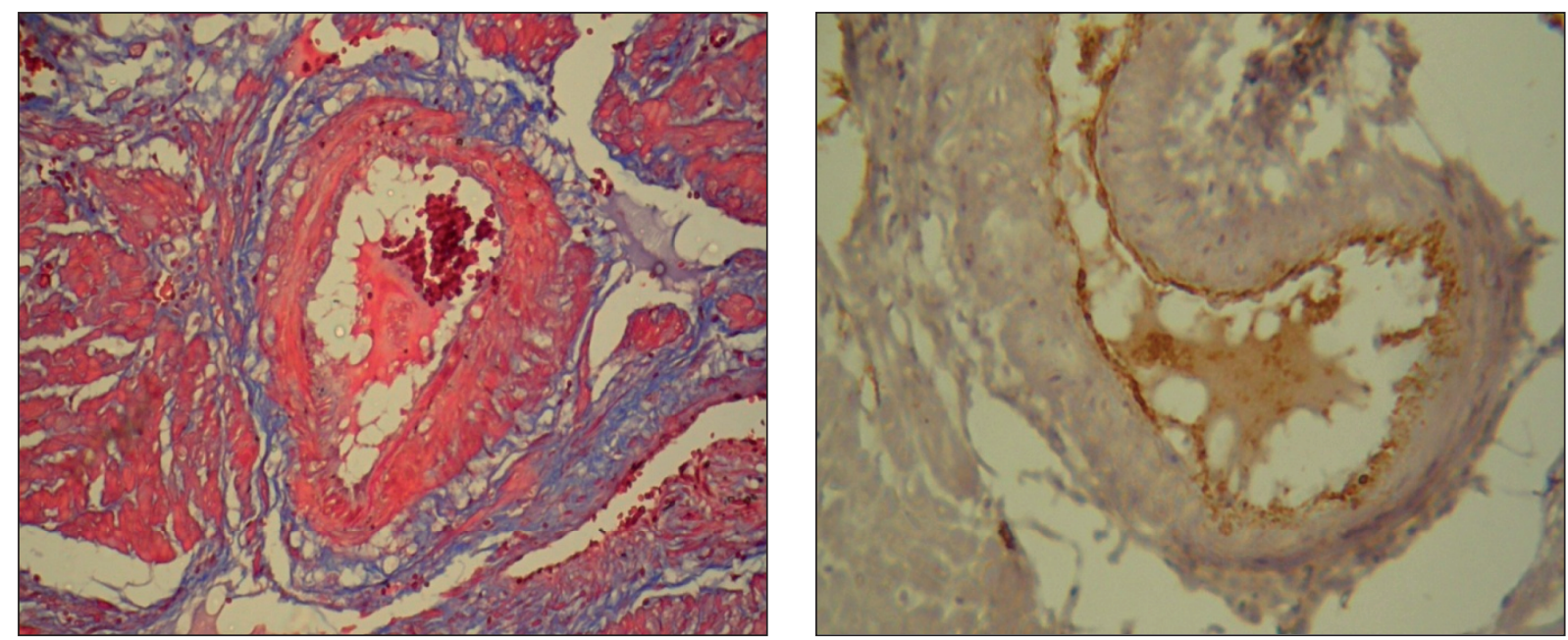

Figure 1. Arterial type vessels Slinchenko's staining (on the left) and immunohistochemical vWF (on the right) staining. Ob $40^{x}$. Oc $10^{x}$
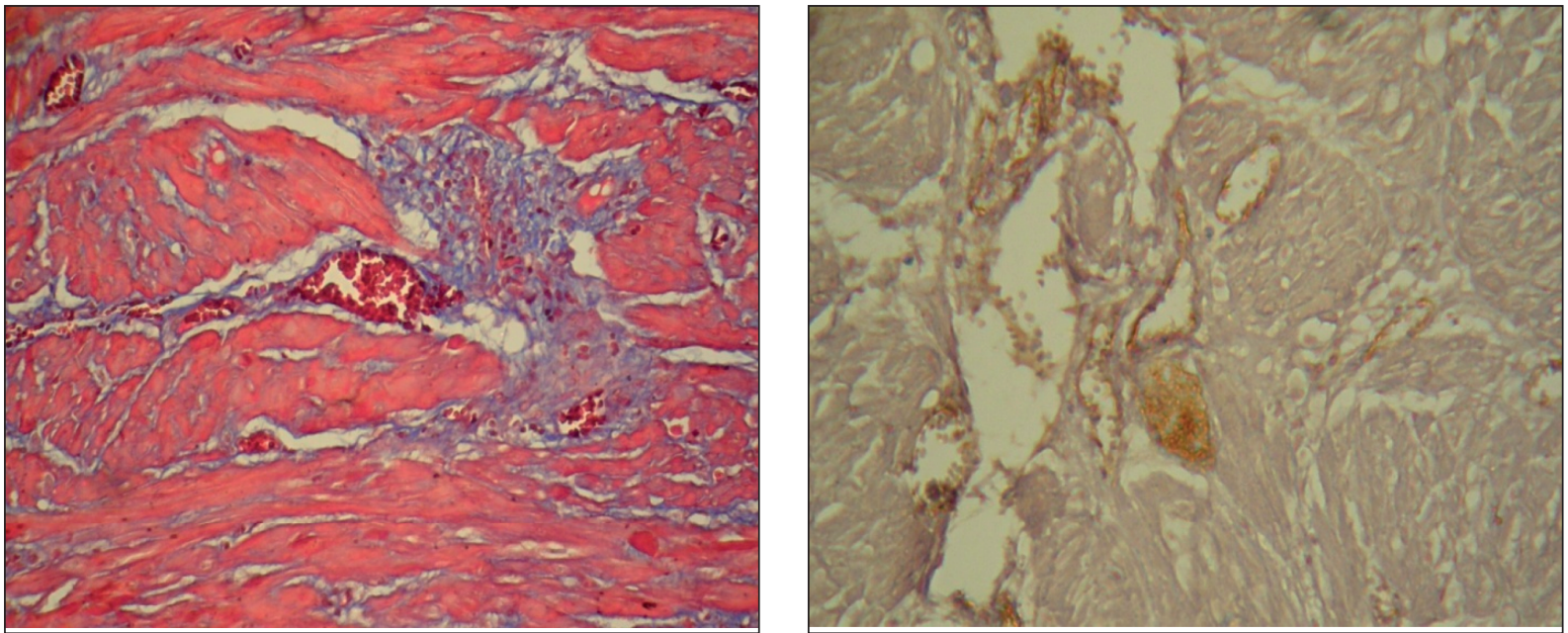

Figure 2. Venous type vessels Slinchenko's staining (on the left) and immunohistochemical vWF (on the right) staining. Ob $10^{x}$. Oc $10^{x}$
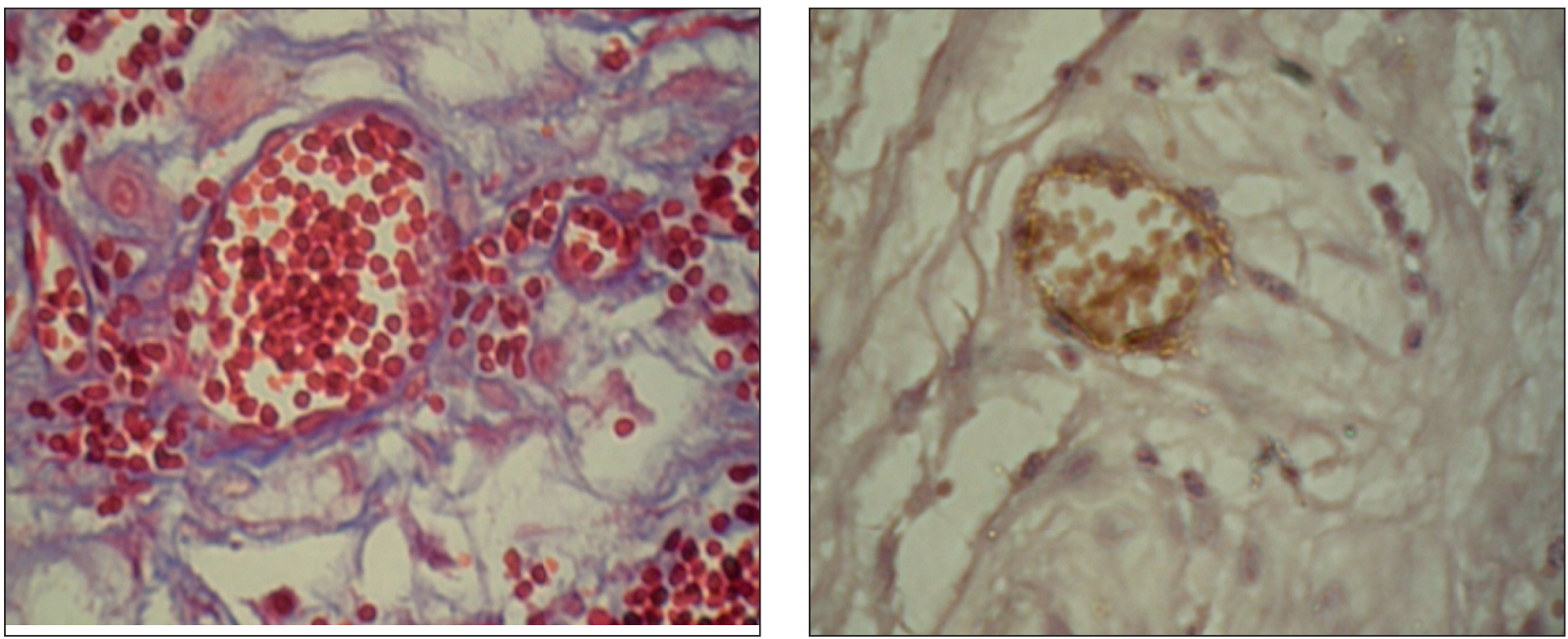

Figure 3. Microcirculatory vessels Slinchenko's staining (on the left) and immunohistochemical vWF (on the right) staining. Ob $40^{x}$. Oc $10^{\times}$ 
these cells, because in a few minutes after the desquamation they are going through the process of anoikis and become round-shaped. After that, the morphological verification of such endothelial cells is mostly impossible. The detection of desquamated endothelial cells witnesses the endothelial dysfunction and indicates the gross damage of the intima of the blood vessel. Therefore, desquamated endothelial cells can be verified by means of detection of vWF.

Another interesting fact was that the groups of erythrocytes in the lumen of the venous vessels and the microcirculatory vessels were stained with the same method, too (Fig. 2,3). According to our assumption, this fact can be an artifact, caused by the insufficient neutralization of erythrocytes peroxidase during the immunohistochemical method. We repeated the study of serial sections of the same myometrium and UPA biopsy with more prolonged neutralization of endoperoxidase and with a double change of neutralizing reagent. The result was the same.

Due to the location of these changes (venous vessels, microcirculatory channel) and staining of only the periphery of erythrocytes, it was concluded that it was caused by the adhesion of vWF on erythrocytes. This can mean the early stage of formation of intravascular blood clots in vessels with a slow blood flow.

\section{Discussion}

The vWF is a plasma glycoprotein, which is one of the key components of hemostasis, contributing to the attachment of blood platelets to damaged areas in the blood vessels ${ }^{18}$. Specific vWF receptors are found both in the plate's membrane and in the sub-endothelium. Since the endothelial cells synthesize vWF more than necessary, this excess is stored inside the endothelial cells in special organelles called WeibelPalade bodies. They excrete vWF after the stimulation of endothelial cells $s^{9,11,12}$.

We drew attention to the lack of information in the scientific literature describing the results of the vWF study in the vessels of the utero-placental area and myometrium in both physiological and complicated pregnancy. In this aspect, we consider to be interesting the study of pregnancy with both blood or cardiovascular diseases and pathology of cytotrophoblastic invasion in the background. For example, iron deficiency anemia leads to low levels of serum iron, changes in red blood cells - hypochromia, microcytosis, spherocytosis, echinocytosis and others contribute to the growth of the intensity of free radical processes, limited proteolysis etc, and in the interstitial spaces of the placenta - increased hemolysis with the release of erythrocytic factors that are involved in fibrin and fibrinogen formation. The pathology of the "mother-placenta-fetus" system may be caused by gestational immaturity of the utero-placental complex, incomplete substitution of the fibrinoid walls of the spiral arteries, hypoperfusion of the interstitial space, violent angiogenesis or hyperplasia of the venous vessels of the utero-placental area. All these factors create prerequisites for increasing endothelial dysfunction both in the vessels of the utero-placental complex, and in the whole organism of the pregnant woman ${ }^{1,9,12}$.

As a result of this study, we found a lower concentration of vWF in endothelial cells of the microcirculatory system, higher concentration of vWF in the endothelial cells of the venous type vessels of the utero-placental area and myometrium (approximately the same amount) and the highest - in arterial type vessels (significantly higher in myometrium) (Table 1).

The prospect of further research is related to the testing of immunohistochemical techniques on the $v W F$ in the UPA and the myometrium of pregnant women with various types of pathology of pregnancy, and first of all, the utero-placental form of placental insufficiency.

\section{Conclusions}

Immunohistochemical study of vWF allows investigation of the endothelial dysfunction in all types of vessels of both UPA and myometrium. This can be very promising for the early detection of placental dysfunction and establishing of morphological preconditions for fetal insufficiency.

We established that immunohistochemical vWF staining on the basis of observation of pregnancy with signs of utero-placental hemocycling pathology reveals early thrombotic formation, blood convection and endothelium damage in myometrium and utero-placental area more efficiently than the classic methods of fibrin staining.

\section{Compliance with Ethics Requirements:}

„The authors declare no conflict of interest regarding this article"

"The authors declare that all the procedures and experiments of this study respect the ethical standards in the Helsinki Declaration of 1975, as revised in 2008(5), as well as the national law. Informed consent was obtained from all the patients included in the study

\section{References}

1. Cuffe JSM, Holland O, Salomon C, Rice GE, Perkins AV. Review: Placental derived biomarkers of pregnancy disorders. Placenta. 2017;54:104-110. 
2. Siddheshware R, Patil SS, Sambarey PW. Clinical correlation with pathology of placenta in medical disorders of pregnancy and its comparison in normal pregnancy. International Journal of Reproduction, Contraception, Obstetrics and Gynecology. 2017;6(1):127-132.

3. Burton GJ, Fowden AL, Thornburg KL. Placental origins of chronic disease. Physiological Reviews. 2016;96(4):1509-1565.

4. Burton GJ, Fowden AL. The placenta: a multifaceted, transient organ. Philosophical transactions of the Royal Society of London. Series B, Biological sciences. 2015;370(1663):20140066.

5. Benirschke K, Burton GJ, Baergen RN: Pathology of the Human Placenta, 6th ed. New York, Springer, 2012:974.

6. Hunt K, Kennedy SH, Vatish M. Definitions and reporting of placental insufficiency in biomedical journals: a review of the literature. European Journal of Obstetrics $\mathcal{E}$ Gynecology and Reproductive Biology. 2016;205:146-149.

7. Andraweera PH, Bobek G, Bowen C, et al. IFPA meeting 2015 workshop report II: mechanistic role of the placenta in fetal programming; biomarkers of placental function and complications of pregnancy. Placenta. 2016;48(Suppl 1):S7-S11.

8. Thornburg KL, Kolahi K, Pierce M, Valent A, Drake R, Louey S. Biological features of placental programming. Placenta. 2016;48(1):S47-S53.

9. Pijnenborg R, Brosens I, Romero R (eds): Placental Bed Disorders: Basic Science and its Translation to Obstetrics. Cambridge, 2010:301.
10. Tiulienieva OA, inventor; Bukovinian State Medical Academy, patent owner. The method of diagnostics of uterine-placental form of failure of extrachorial type. Patent of Ukraine $\mathrm{N}^{\circ}$ 60921. 2003, October, 15.

11. Haberichter SL. Von Willebrand factor propeptide: biology and clinical utility. Blood. 2015;126(15):1753-1761.

12. Ilika V, Davydenko I. Optical density quantitative parameters of the immunohistochemical staining on the von Willebrand factor in the endothelium and fibrinoid of the placenta in connection with the secundaries inflammation and iron deficiency anemia in gravidas. Georgian Medical News. 2017;273:108-113.

13. Burton GJ, Jauniaux E. The cytotrophoblastic shell and complications of pregnancy. Placenta. 2017;60:134-139.

14. Ptacek I, Sebire NJ, Man, JA, Brownbill P, Heazell AE. Systematic review of placental pathology reported in association with stillbirth. Placenta. 2014;35(8):552-562.

15. Fajersztajn L, Veras MM. Hypoxia: from placental development to fetal programming. Birth Defects Research. 2017;109(17):1377-1385.

16. Ferreira T, Rasband W. Image J User Guide. New York, National Institute of Health, 2012:187.

17. Hammer $\varnothing$. PAST: Paleontological Statistics. Version 3.19. Reference Manual. Oslo, Natural History Museum University of Oslo, 2018:259.

18. Diaconu C, Balaceanu A, Bartos D. Venous thromboembolism in pregnant woman - a challenge for the clinician. Central European Journal of Medicine. 2013;8(5):548-552. 